\title{
Development of a multidimensional labour satisfaction questionnaire: dimensions, validity, and internal reliability
}

\author{
L F P Smith
}

\begin{abstract}
Background-No published quantitative instrument exists to measure maternal satisfaction with the quality of different models of labour care in the UK.

Methods-A quantitative psychometric multidimensional maternal satisfaction questionnaire, the Women's Views of Birth Labour Satisfaction Questionnaire (WOMBLSQ), was developed using principal components analysis with varimax rotation of successive versions. Internal reliability and content and construct validity were assessed.

Results-Of 300 women sent the first version (WOMBLSQ1), 120 (40\%) replied; of 300 sent WOMBLSQ2, $188(62.7 \%)$ replied; of 500 women sent WOMBLSQ3, 319 $(63.8 \%)$ replied; and of 2400 women sent WOMBLSQ4, $1683(70.1 \%)$ replied. The latter two versions consisted of 10 dimensions in addition to general satisfaction. These were (Cronbach's alpha): professional support in labour $(0.91)$, expectations of labour (0.90), home assessment in early labour (0.90), holding the baby (0.87), support from husband/partner $(0.83)$, pain relief in labour $(0.83)$, pain relief immediately after labour (0.65), knowing labour carers (0.82), labour environment $(0.80)$, and control in labour $(0.62)$. There were moderate correlations (range 0.16-0.73) between individual dimensions and the general satisfaction scale $(0.75)$. Scores on individual dimensions were significantly related to a range of clinical and demographic variables. Conclusion-This multidimensional labour satisfaction instrument has good validity and internal reliability. It could be used to assess care in labour across different models of maternity care, or as a prelude to in depth exploration of specific areas of concern. Its external reliability and transferability to care outside the South West region needs further evaluation, particularly in terms of ethnicity and social class.

(Quality in Health Care 2001;10:17-22)
\end{abstract}

Keywords: Women's Views of Birth Labour Satisfaction Questionnaire (WOMBLSQ); labour; questionnaire

Maternal and perinatal mortality are the traditional national and international measures of the quality of labour care. Fortunately, maternal deaths have become extremely rare and perinatal mortality and morbidity such as
Key messages

- A quantitative multidimensional maternal labour satisfaction questionnaire has been developed which comprises 10 dimensions in addition to general satisfaction.

- It possesses good internal reliability and validity, but its generalisability and external reliability need further testing.

- It could be used to compare models or systems of labour care as a stand alone instrument, or as a screening test prior to in depth qualitative work.

What this paper adds to the subject To date there has been no published multidimensional satisfaction instrument to assess labour care. This instrument could be used in addition to standard measures of labour care, such as perinatal mortality and maternal morbidity, to give a more rounded overall picture of the care which women receive in labour in the $\mathrm{UK}$.

cerebral palsy are insensitive indicators of various components of pregnancy care. ${ }^{1}$ For a full picture of the quality of labour care one needs a patient centred measure such as women's satisfaction.

Measurement of patient satisfaction is not easy. ${ }^{2-5}$ To compare between women, institutions, or aspects of labour care, a quantitative measure is needed. ${ }^{6}$ Medical and nursing psychometric satisfaction measures exist, ${ }^{7-11}$ but only one has been published for (antenatal) maternity care. ${ }^{12}$ When designing a satisfaction questionnaire (instrument) one must consider a range of potential dimensions ${ }^{36^{13-17}}$ including continuity of care, availability of carers, access, interpersonal skills, and technical competence. ${ }^{2} 78$ 18-22 "Home made" satisfaction questionnaires tend to overestimate satisfaction, as do those which ask questions about satisfaction in general terms. ${ }^{13}{ }^{23}$

Care in childbirth continues to evolve-for example, following publication of the "changing childbirth" report ${ }^{24}$ - and there are still many organisational models for labour. ${ }^{25} 26$ Because these models emphasise various aspects of care-such as greater continuity, greater accessibility, and greater shared care-or provide care at different sites and/or from different professional groups, there is a need to have a valid reliable multidimensional questionnaire to assess the quality of labour 
care from a woman's perspective. Such assessment could allow future models of care to be more focused on women's specific needs, not just on the needs of the professionals or the "maternity care system". This paper describes the development of such a questionnaire, the Women's Views of Birth Labour Satisfaction Questionnaire (WO $\bar{M} B L S \bar{Q})$.

\section{Method}

FACE AND CONTENT RELIABILITY

There were three development versions of the WOMBLSQ proper, resulting in a fourth or final version (WOMBLSQ4). Questions were selected from five sources to ensure content and face validity. These were fieldwork, a published survey manual, ${ }^{27}$ the North American PSQ-III satisfaction questionnaire, ${ }^{28}$ specially written questionnaires from an initial literature review, and further new questions were added after version 2 was tested (see below). The original fieldwork (reported elsewhere) ${ }^{29}{ }^{30}$ enabled us to discard or to rewrite questions which were frequently skewed or not answered. WOMBLSQ2 contained open questions which were analysed to ensure that no important areas were being excluded from the questionnaire. If this was so, the missing content areas were added to WOMBLSQ3.

Many questions were deliberately very positively or negatively worded to enhance the respondents' ability to express minimal dissatisfaction. ${ }^{13}$ All "questions" were statements which required respondents to mark a seven point Likert scale from "totally disagree" to "totally agree" to enhance the sensitivity of subsequent dimensions. ${ }^{6} 1316$

The questionnaire was developed over 4 years in several NHS trusts and general practices in the old South West region of England. WOMBLSQ1 was tested in three trusts,
WOMBLSQ2 and 3 in nine trusts, and WOMBLSQ 4 in three different trusts. Midwives were asked to give questionnaires to consecutive women postnatally within 10 days of birth. This included women who had delivered at home, in community units, or large hospitals. Except for WOMBLSQ4 which was posted 6-12 weeks postnatally to consecutive women on a list of births, no reminders were used. WOMBLSQ3 and 4 had additional sections on demography and pregnancy details to judge the generalisability of results and to allow testing of construct validity.

\section{INTERNAL RELIABILITY}

Questionnaires were analysed using the SPSS-PC statistical package. Repeated stepwise principal components analysis (PCA) with varimax rotation was used to produce factors (dimensions), ${ }^{31} 32$ each of which consisted of one or more questions which were then re-read as a group intuitively to label the dimensions. The aim was to evolve groups of questions which each addressed a specific dimension. This procedure has been used in a similar situation to produce an antenatal satisfaction questionnaire ${ }^{12}$ and other patient satisfaction questionnaires. ${ }^{78}$

The remaining questions were then checked to ensure content validity. New questions were added where either important topic areas were missing following the statistical analysis (reduced content validity) or where the internal reliability of a dimension was low and the next version evolved.

\section{SCALE GENERATION}

Scale scores were generated to allow easily comprehensible comparisons between individual dimensions. This is important if the questionnaire is to be used to assess the relative

Table 1 Parameters of the final and three development versions of the labour satisfaction questionnaires

\begin{tabular}{|c|c|c|c|c|c|c|c|c|c|c|c|c|}
\hline & \multicolumn{3}{|c|}{ WOMBLSQ1 } & \multicolumn{3}{|c|}{ WOMBLSQ2 } & \multicolumn{3}{|c|}{ WOMBLSQ3 } & \multicolumn{3}{|c|}{ WOMBLSQ4 } \\
\hline & Pre-test & \multicolumn{2}{|c|}{ Post-analysis } & Pre-test & \multicolumn{2}{|c|}{ Post-analysis } & Pre-test & \multicolumn{2}{|c|}{ Post-analysis } & Pre-test & \multicolumn{2}{|c|}{ Post-analysis } \\
\hline Year tested & 1995 & & & 1996 & & & 1997 & & & 1998 & & \\
\hline Respondents & 300 & 120 & & 300 & 188 & & 500 & 319 & & 2400 & 1438 & \\
\hline Factors (dimensions) $)^{\star}$ & 11 & 10 & & 10 & 11 & & 15 & 10 & & 10 & 10 & \\
\hline Overall Cronbach alpha* & - & 0.6 & & - & 0.7 & & - & 0.8 & & - & & \\
\hline KMO statistic & - & 0.7 & & - & 0.7 & & - & 0.8 & & - & & \\
\hline Bartlett, $\mathrm{p}$ value & - & $<0.0$ & & - & $<0.0$ & & - & $<0.0$ & & - & $<0$ & \\
\hline \multirow[t]{2}{*}{$\%$ variance explained } & - & 82.9 & & - & 72.7 & & - & 75.9 & & - & 77 & \\
\hline & \multicolumn{2}{|c|}{ No of questions } & \multirow[t]{2}{*}{ Alpha } & \multicolumn{2}{|c|}{ No of questions } & \multirow[t]{2}{*}{ Alpha } & \multicolumn{2}{|c|}{ No of questions } & \multirow[t]{2}{*}{ Alpha } & \multicolumn{2}{|c|}{ No of questions } & \multirow[t]{2}{*}{ Alpha } \\
\hline Factors (dimensions) & 82 & 25 & & 39 & 29 & & 50 & 32 & & 32 & 32 & \\
\hline Professional competence & 10 & 5 & 0.91 & 5 & 4 & 0.88 & 4 & 5 & 0.89 & 5 & 5 & 0.91 \\
\hline Expectations & 3 & 3 & 0.91 & 3 & 4 & 0.92 & 4 & 4 & 0.90 & 4 & 4 & 0.90 \\
\hline Knowing carers & 7 & 2 & 0.87 & 2 & 2 & 0.82 & 2 & 2 & 0.83 & 2 & 2 & 0.82 \\
\hline Interpersonal skills & 10 & 0 & & & & & & & & & & \\
\hline Pain in labour & 4 & 2 & 0.58 & 5 & 2 & 0.69 & 3 & 3 & 0.80 & 3 & 3 & 0.83 \\
\hline Communications & 9 & 2 & 0.62 & 6 & 3 & 0.83 & 3 & 0 & & & & \\
\hline Time & 6 & 1 & N/A & 3 & 0 & & & & & & & \\
\hline Access & 4 & 0 & & 0 & 1 & N/A & 1 & 0 & & & & \\
\hline Organisation of carers & 2 & 0 & & & & & & & & & & \\
\hline Information & 3 & 2 & 0.79 & 2 & 1 & N/A & 4 & 0 & & & & \\
\hline Delivery details/care & 17 & 0 & & & & & & & & & & \\
\hline Satisfaction & 7 & 2 & 0.87 & 2 & 2 & 0.82 & 2 & 2 & 0.72 & 2 & 2 & 0.75 \\
\hline Environment & 0 & 2 & 0.84 & 2 & 2 & 0.78 & 2 & 2 & 0.85 & 2 & 2 & 0.80 \\
\hline Home assessment & 0 & 2 & 0.39 & 6 & 3 & 0.79 & 3 & 3 & 0.88 & 3 & 3 & 0.90 \\
\hline Pain after labour & 0 & 2 & 0.51 & 3 & 2 & 0.64 & 3 & 3 & 0.67 & 3 & 3 & 0.65 \\
\hline Holding baby & & & & 0 & 3 & 0.84 & 3 & 3 & 0.79 & 3 & 3 & 0.87 \\
\hline Husband support & & & & & & & 4 & 3 & 0.78 & 3 & 3 & 0.83 \\
\hline Control & & & & & & & 4 & 2 & 0.55 & 2 & 2 & 0.62 \\
\hline Being left alone & & & & & & & 5 & 0 & & & & \\
\hline Postnatal care & & & & & & & 3 & 0 & & & & \\
\hline
\end{tabular}

Excluding "a general satisfaction" dimension at all stages.

"Pre-test" refers to the state of the questionnaire as it was sent out to respondents; "post-analysis" refers to the reduced questionnaire after analysis. 
strengths and weaknesses of various aspects of labour care. To produce a scale score for each of the dimensions identified, constituent scale questions were added (with negatively worded questions being reversed). This total was then transformed so that the minimum possible score was always 0 (total dissatisfaction with that dimension) and the maximum possible score $100 \%$ (total satisfaction with that dimension).

CONSTRUCT VALIDITY

Construct validity should be assessed by examining the compatibility of dimensions with primary research evidence about how different groups of women should score. In addition, individual dimensions were tested against the transformed general satisfaction dimension. There should be moderate correlation between dimensions which are related to, but distinct from, "satisfaction" as a global concept. ${ }^{8} 9$

The transformed individual dimensions were tested against (1) depression (on the Edinburgh Postnatal Depression scale of 0-20 with a higher score indicating more severe depression) and age (years) (Pearson correlation coefficients calculated); (2) duration of breast feeding (recorded on an ordinal scale of: never attempted, tried only a few times, breast fed but now discontinued, still breast feeding but mixed; solely breast feeding), educational level (primary or secondary school, sixth form/ college, professional or technical qualification, diploma, degree course) and social class (unskilled manual, partly skilled manual, skilled manual, skilled non-manual, professional/managerial) (Spearman correlation coefficients calculated); and (3) place of delivery (home, small community unit, large hospital), parity (multiparous or primiparous), induction of labour (yes/no), mode of delivery (vaginal delivery, forceps/Ventouse delivery, caesarean section), and labour complications (yes/no) (one way analysis of variance followed by Student-Newmann-Keuls (SNK) post hoc tests if appropriate). Because of the large number of comparisons being analysed the $p$ value was set at $1 \%$.

The study was approved by the relevant local research ethics committees.
Table 2 Demographic variables of women who responded to versions 3 and 4 of the labour satisfaction questionnaire

\begin{tabular}{|c|c|c|c|c|}
\hline \multirow[b]{2}{*}{ Demographic variable } & \multicolumn{2}{|c|}{ WOMBLSQ3 } & \multicolumn{2}{|c|}{ WOMBLSQ4 } \\
\hline & $n$ & $\%$ & $n$ & $\%$ \\
\hline Education & 376 & & 1683 & \\
\hline Primary/secondary & 112 & 30.3 & 512 & 30.8 \\
\hline College & 83 & 22.4 & 323 & 19.4 \\
\hline Professional/technical & 78 & 21.1 & 338 & 20.3 \\
\hline Diploma & 25 & 6.8 & 167 & 10.0 \\
\hline Degree & 72 & 19.5 & 322 & 19.4 \\
\hline Not known & 6 & & 21 & \\
\hline Social class & 376 & & 1683 & \\
\hline Unskilled & 24 & 7.1 & 65 & 4.2 \\
\hline Partly skilled & 28 & 8.3 & 119 & 7.6 \\
\hline Semi-skilled manual & 82 & 24.4 & 378 & 24.3 \\
\hline $\begin{array}{l}\text { Semi-skilled } \\
\text { non-manual }\end{array}$ & 44 & 13.1 & 213 & 13.7 \\
\hline $\begin{array}{l}\text { Professional/ } \\
\text { managerial }\end{array}$ & 158 & 47.0 & 782 & 50.2 \\
\hline Others/not known & 40 & & 126 & \\
\hline Employment & 353 & & 1646 & \\
\hline Full time & 182 & 51.6 & 714 & 43.4 \\
\hline Part time & 74 & 21.0 & 481 & 29.2 \\
\hline Unemployed & 97 & 27.5 & 451 & 27.4 \\
\hline
\end{tabular}

\section{Results}

DEVELOPMENT

The details of the four versions of WOMBLSQ are given in table 1 . Analysis of open questions in WOMBLSQ2 suggested four missing content areas: relevant questions were added to WOMBLSQ3. These were support from one's husband or partner, being in control or not, being left alone, and immediate postnatal care; only two of these were retained after analysis of version 4.

RESPONDENTS

WOMBLSQ3 was sent out to 500 women in nine trusts of whom $319(63.8 \%)$ replied. WOMBLSQ4 was sent to 2400 women in three trusts of whom $1683(70.1 \%)$ replied. Respondents to both were comparable with respect to social class, educational level, and employment in early pregnancy (table 2 ). The clinical details of the respondents to both of these postings are as follows.

\section{WOMBLSQ3}

Of 376 respondents (mean (SD) age 29.1 (5.82) years, range 15-45), 346 (92.5\%) were living with their husband or partner, 365 $(98.1 \%)$ were of white ethnic origin, 189 (51.6\%; 10 not known) were primiparous, 298 (79.7\%; two not known) had a vaginal delivery,

Table 3 Matrix of correlation coefficients for WOMBLSQ4 between all scales

\begin{tabular}{|c|c|c|c|c|c|c|c|c|c|c|c|}
\hline & $\begin{array}{l}\text { Professional } \\
\text { support }\end{array}$ & Expectations & $\begin{array}{l}\text { Home } \\
\text { assessment }\end{array}$ & $\begin{array}{l}\text { Holding } \\
\text { baby }\end{array}$ & $\begin{array}{l}\text { Husband } \\
\text { support }\end{array}$ & $\begin{array}{l}\text { Pain in } \\
\text { labour }\end{array}$ & $\begin{array}{l}\text { Pain after } \\
\text { labour }\end{array}$ & $\begin{array}{l}\text { Knowing } \\
\text { carer }\end{array}$ & Environment & Control & $\begin{array}{l}\text { General } \\
\text { satisfaction }\end{array}$ \\
\hline $\begin{array}{c}\text { Professional } \\
\text { support }\end{array}$ & - & 0.418 & 0.203 & 0.392 & 0.282 & 0.542 & 0.292 & 0.332 & 0.477 & 0.224 & 0.729 \\
\hline Expectations & & - & 0.173 & 0.344 & 0.148 & 0.378 & 0.273 & 0.236 & 0.417 & 0.095 & 0.484 \\
\hline $\begin{array}{l}\text { Home } \\
\text { assessment }\end{array}$ & & & - & 0.144 & $0.077^{\star}$ & 0.260 & 0.172 & 0.133 & 0.251 & $0.053^{\star \star}$ & 0.269 \\
\hline Holding baby & & & & - & 0.236 & 0.302 & 0.225 & 0.096 & 0.334 & $0.020^{\star \star \star}$ & 0.325 \\
\hline $\begin{array}{l}\text { Husband } \\
\text { support }\end{array}$ & & & & & - & 0.208 & 0.147 & $0.034^{\star \star \star}$ & 0.175 & $0.069^{\star \star}$ & 0.228 \\
\hline Pain in labour & & & & & & - & 0.286 & 0.187 & 0.306 & $0.027^{\star \star \star}$ & 0.554 \\
\hline Pain after labour & & & & & & & - & 0.100 & 0.229 & $0.030^{\star \star \star}$ & 0.273 \\
\hline Knowing carer & & & & & & & & - & 0.284 & 0.104 & 0.331 \\
\hline Environment & & & & & & & & & - & 0.130 & 0.482 \\
\hline Control & & & & & & & & & & - & 0.160 \\
\hline Satisfaction & & & & & & & & & & & - \\
\hline
\end{tabular}

All are significant at $\mathrm{p}<0.001$ except ${ }^{\star} \mathrm{p}<0.01,{ }^{\star \star} \mathrm{p}<0.05,{ }^{\star \star \star} \mathrm{p}=\mathrm{NS}$. Minimum $\mathrm{n}$ for all correlations in table $=1513$. 
Table 4 Mean satisfaction scores (\%) on five subscales categorised by women's place of delivery

\begin{tabular}{|c|c|c|c|c|c|c|c|c|}
\hline Subscale & Home & $\begin{array}{l}\text { Community } \\
\text { unit }(C U)\end{array}$ & $\begin{array}{l}\text { Large Hospital } \\
(\mathrm{LH})\end{array}$ & F value & $S D$ & $d f$ & $p$ value & $\begin{array}{l}\text { Significant differences on post-hoc testing } \\
(p<0.05)\end{array}$ \\
\hline Expectations & 84.3 & 68.6 & 54.8 & 19.6 & 25.8 & 2,350 & 0.0001 & Home $v$ CU; home $v$ LH; CU $v$ LH \\
\hline Professional support & 92.3 & 80.3 & 78.4 & 7.0 & 16.8 & 2,357 & 0.001 & Home $v$ CU; home $v$ LH \\
\hline Pain in labour & 63.5 & 55.9 & 54.5 & 5.9 & 11.7 & 2,351 & 0.01 & Home $v$ CU; home $v$ LH \\
\hline Knowing carer & 84.1 & 46.2 & 38.4 & 25.8 & 28.5 & 2,356 & 0.0001 & Home $v$ CU; home $v$ LH; CU $v$ LH \\
\hline Control & 64.8 & 44.8 & 49.2 & 6.3 & 23.7 & 2,350 & 0.002 & Home $v \mathrm{CU}$; home $v \mathrm{LH}$ \\
\hline
\end{tabular}

$32(8.6 \%)$ had an instrumental delivery, 44 $(11.8 \%)$ had caesarean section, 77 (20.7\%; four not known) had their labour induced, 123 (33.1\%) had labour complications, 251 $(69.1 \% ; 13$ not known) planned to deliver in a large hospital, $90(24.8 \%)$ in a community unit, and $22(6.1 \%)$ at home; mean (SD) gestation at birth was 39.8 (1.55) weeks (range 33-43).

\section{WOMBLSO4}

Of 1683 respondents, 1420 (86.4\%) were screen negative on the Edinburgh Postnatal Depression scale with 40 women not answering the question; $317(19 \% ; 14$ not known) never attempted breast feeding, $146(8.7 \%)$ tried for a short period but quickly gave up, 534 $(32.0 \%)$ breast fed for some weeks, 407 $(24.4 \%)$ were still breast feeding in addition to other milk, 265 (15.9\%) were still exclusively breast feeding when surveyed.

\section{DIMENSIONS AND INTERNAL RELIABILITY}

PCA of the WOMBLSQ3 respondents suggested 11 dimensions comprising 32 questions, including general satisfaction (two questions). These were (table 1): professional support, women's expectations, knowing carers, pain in labour, labour environment, home assessment in early labour, pain immediately after labour, holding the baby, being in control, and support from husband/partner. PCA of the WOMBLSQ4 respondents confirmed these dimensions. Each of the 30 questions highly loaded onto only one dimension (see appendix).

The overall reliability of the total scale excluding general satisfaction was good with Cronbach's alpha of 0.860 and 0.892 , respectively, and values for individual dimensions of $0.55-0.90$ and $0.62-0.91$, respectively, for WOMBLSQ3 and WOMBLSQ4.
CONSTRUCT VALIDITY

The individual dimensions of WOMBLSQ4 were tested against the general satisfaction scale and found to be moderately correlated (table 3). Intercorrelations between dimensions were mostly acceptable.

Planned place of delivery was significantly associated with satisfaction with professional support, expectations of labour, pain in labour, knowing carer, and control subscales (table 4). Those women whose labour was induced were less likely to be satisfied with their expectations of labour subscale $(\mathrm{F}=16.38, \mathrm{df}=1,360$; $\mathrm{p}<0.0001 ; 49.3 \%$ v $63.2 \%$ for those not induced). Primiparous women were less likely to be satisfied with their expectations of labour $(\mathrm{F}=33.8, \mathrm{df}=1,353 ; \mathrm{p}<0.0001 ; 52.7 \%$ v $68.5 \%)$ and with knowing their carers in labour $(\mathrm{F}=6.81, \mathrm{df}=1,360 ; \mathrm{p}<0.01 ; 38.5 \%$ v $46.9 \%)$. Type of delivery was also related to satisfaction with expectations of labour $(\mathrm{F}=95.96, \mathrm{df}=2$, $360 ; \mathrm{p}<0.0001)$ and with pain after delivery $(\mathrm{F}=7.15, \mathrm{df}=2,368 ; \mathrm{p}<0.001)$. Women having a vaginal delivery were more satisfied with their expectations of labour $(68.0 \%)$ than those having instrumental delivery $(32.3 \%)$ and those having a caesarean section $(24.1 \%)$. Women having a vaginal delivery $(48.9 \%)$ were also more satisfied with their pain relief immediately after delivery than those having a caesarean section (40.4\%), but not than those having an instrumental delivery $(44.1 \%)$. Maternal age and gestation at delivery were unrelated to any of the satisfaction subscales.

Respondents to WOMBLSQ4 had a range of postnatal depression scores. These were significantly negatively correlated with the satisfaction scale $(p<0.001)$ and all subscales $(p<0.001)$ except knowing carer $(p>0.05)$ and control ( $\mathrm{p}>0.05$; table 5). Duration of breast

Table 5 Testing of construct validity of dimensions against depression, breast feeding, best educational level attained, social class of head of household, place of delivery, parity, whether labour induced, mode of delivery, labour complications and age

\begin{tabular}{|c|c|c|c|c|c|c|c|c|c|}
\hline \multirow[b]{2}{*}{ Dimensions } & \multicolumn{5}{|c|}{ WOMBLSQ3 } & \multicolumn{4}{|c|}{ WOMBLSQ4 } \\
\hline & $\begin{array}{l}\text { Place of } \\
\text { delivery }^{c}\end{array}$ & Parity $^{c}$ & $\begin{array}{l}\text { Labour } \\
\text { induced }^{c}\end{array}$ & $\begin{array}{l}\text { Mode of } \\
\text { delivery }^{c}\end{array}$ & $\begin{array}{l}\text { Labour } \\
\text { complications }^{c} \text { Age }^{a}\end{array}$ & Depression $^{a}$ & $\begin{array}{l}\text { Breast } \\
\text { feeding }\end{array}$ & $\begin{array}{l}\text { Educational } \\
\text { level } \\
\text { attained }^{b}\end{array}$ & Social class ${ }^{b}$ \\
\hline $\begin{array}{l}\text { Professional } \\
\text { support }\end{array}$ & $\star \star$ & & & & & $\star \star$ & * & & \\
\hline Expectations & $\star \star$ & $\star \star$ & $\star \star$ & $\star \star$ & $\star \star$ & $\star \star$ & & $\star$ & $\star \star$ \\
\hline Home assessment & & & & & & $\star \star$ & & & \\
\hline Holding baby & & & & & & $\star \star$ & $\star \star$ & & \\
\hline Husband support & & & & & & $\star \star$ & & & $\star$ \\
\hline Pain in labour & $\star$ & & & & & $\star \star$ & $\star \star$ & & \\
\hline Pain after labour & & & & & $\star \star$ & $\star \star$ & $\star \star$ & & \\
\hline Knowing carer & $\star \star$ & $\star$ & & & & & $\star$ & $\star \star$ & $\star \star$ \\
\hline Environment & & & & & & $\star \star$ & & $\star \star$ & $\star \star$ \\
\hline Control & $\star$ & & & & & & $\star \star$ & $\star \star$ & $\star \star$ \\
\hline $\begin{array}{l}\text { General } \\
\text { satisfaction }\end{array}$ & & & & & & $\star \star$ & & $\star$ & \\
\hline
\end{tabular}

${ }^{\star} \mathrm{p}<0.01 ;{ }^{\star \star} \mathrm{p}<0.001$ (see text for details).

${ }^{\mathrm{a} P e a r s o n}$ correlation coefficient; ${ }^{\mathrm{b}} \mathrm{Spearman}$ rho; ${ }^{\mathrm{c}}$ one way analysis of variance. 
feeding was positively associated with increasing satisfaction for subscales of professional support, holding her baby, pain in labour, pain after labour, and being in control; it was significantly negatively associated with knowing her carer. Higher educational achievement was negatively correlated with satisfaction on the expectation subscale, knowing carer, and environment subscale; it was significantly positively correlated on the control subscale. Higher social class was significantly positively correlated with the husband/partner support subscale; it was significantly negatively correlated with satisfaction with expectation subscale, knowing carer, and labour environment subscale.

\section{Discussion}

This study has produced a new valid reliable instrument with which to assess women's satisfaction with their labour care, and hence strengthen assessment of the quality of labour care. It is short and easily completed by women following delivery or by post. It could be used to evaluate different care models, ideally jointly with neonatal and maternal morbidity following labour to produce a satisfaction score (either a total overall score or one based on its various dimensions), or as a screening instrument to focus efficiently qualitative exploration in areas of low satisfaction from women's perspective. "One off "evaluation is limited as reference ranges have yet to be developed.

The WOMBLSQ has good content validity with questions developed from a review of the literature, interview fieldwork, ${ }^{29}{ }^{30}$ existing instruments, ${ }^{27} 28$ and women's comments. It also has construct validity: its dimensions relate to a range of clinical and demographic variables which previous work has suggested alter women's perceptions of their labour care: knowing one's carer, ${ }^{14} 151821$ place of delivery, ${ }^{27} 28$ expectations of labour care, ${ }^{33}$ professional competence, ${ }^{7}{ }^{14} 15$ and pain during labour. ${ }^{34}$ There is no published evidence to support the pain following delivery and the husband support subscales, but these developed out of women's comments.

As one might expect, the instrument can discriminate between women giving birth in different settings (home, community units, large hospitals), having different types of birth, and having a range of problems including induction of labour and complications. ${ }^{18} 2728$ As expected, both social class ${ }^{30}$ and highest level of education $^{13}$ attainment affected some of the dimensions of satisfaction but these differences are difficult to interpret. Each of the dimensions was moderately correlated with overall satisfaction, but not too strongly; if this was the case, it is likely that such a subscale would be measuring general satisfaction rather than a component of it. ${ }^{89}$

The WOMBLSQ has good internal reliability when viewed as one scale or when assessed on its individual subscales. Two of the subscales have a Cronbach's alpha of $<0.7 .{ }^{35} \mathrm{It}$ may be that these two scales need further development. Overall, the good alpha figures suggest that the dimensions are internally consistent and also separate from "global satisfaction".

The instrument still has some weaknesses. Further work is needed to assess its test-retest reliability and its generalisability; the respondents were predominately of middle social class, in stable relationships, and of good educational achievement. However, it is sufficiently robust to be used in evaluating service developments as one component of assessing the quality of labour care that women receive.

1 Bakketeig LS. Only a minor part of cerebral palsy cases begin in labour. BMF 1999;319:1016-7.

2 Williams SJ, Calnan M. Key determinants of consumer satisfaction with general practice. Fam Pract 1991;8:237-42.

3 Hall JA, Dornan MC. Meta-analysis of satisfaction with medical care: description of research domain and analysis of overall satisfaction levels. Soc Sci Med 1988;27:637-44.

4 Streiner DL, Dornan MC. What patients like about their medical care and how often they are asked: a meta-analysis of the satisfaction literature. Soc Sci Med 1988;29:935-9.

5 Seguin L, Therrieu R, Champagne F, et al. The components of women's satisfaction with maternity care. Birth 1989;16: $109-13$

6 Carr-Hill RA. The measurement of patient satisfaction. $\mathcal{f}$ Publ Health Med 1992;14:236-49.

7 Baker R. Development of a questionnaire to assess patients' satisfaction with consultations in general practice. $\mathrm{Br} \mathcal{F} \mathrm{Gen}$ Pract 1990;40:487-90.

8 Baker R. The reliability and criterion validity of a measure of patients' satisfaction with their general practice. Fam Pract 991;8:171-7

9 McKinley RK, Manku-Scott T, Hastings AM, et al. Reliability and validity of a new measure of patient satisfaction with out of hours primary medical care in the UK: development of a patient questionnaire. BMF 1997;314:193-8.

10 Grogan S, Connor M, Willits D, et al. Development of a questionnaire to measure patients satisfaction with GP services. Br F Gen Pract 1995;45:525-9.

11 Poulton BC. Use of the consultation satisfaction questionnaire to examine patient's satisfaction with GPs and community nurses: reliability, replicability and discriminant validity. Br f Gen Pract 1996;46:26-31.

12 Smith LFP. The WOMB antenatal satisfaction questionnaire: development, dimensions, internal reliabilquestionnaire: development, dimensions, inter

13 Lewis JR. Patient views on quality care in general practice: literature review. Soc Sci Med 1994;39:655-70.

14 Chang K. Dimensions and indicators of patients' perceived nursing care quality in the hospital setting. F Nurs Qual 1997;11:26-37.

15 Mahon PY. An analysis of the concept patient satisfaction as it relates to contemporary nursing care. $\mathcal{F} A d v$ Nurs $1996 ; 24: 1241-8$

16 Streiner DL, Norman GR. Health measurement scales: a practical guide to their development and use. Oxford Medical Publications, 1994.

17 Williams B. Patient satisfaction: a valid concept? Soc Sci Med 1994;38:509-16.

18 Flint C, Poulengeris P, Grant A. The "know your midwife" scheme: a randomised trial of continuity of care by a team scheme: a randomised trial of contin
of midwives. Midwifery 1989;5:11-6.

19 Kowalski K, Gottschalk J, Greer B, et al. Team nursing coverage of prenatal/intrapartum patients at a university hospital. Obstet Gynaecol 1977;50:116-9.

20 Powers KA, McCloskey CR. The childbearing experience: a prototype for the study of continuity of care. Issues Comprehensive Paediatr Nursing 1981;5:53-66.

21 Kojo-Austin H, Malin M, Hemminki E. Women's satisfaction with maternity health care services in Finland. Soc Sci Med 1993;37:633-8.

22 Williams SJ, Calnan M. Key determinants of consumer satisfaction with general practice. Fam Pract 1991;8:237-42.

23 Locker D, Dunt D. Theoretical and methodological issues in sociological studies of consumer satisfaction with medical care. Soc Sci Med 1978;12:283-92.

24 Report of the Expert Maternity Group (The "Cumberlege Report"). London: HMSO, 1993 .

25 Allen I, Bourke Dowling S, Williams S. A leading role for midwives? Evaluation of midwifery group practice development projects. London: Policy Studies Institute, 1997.

26 Garcia J. Changing midwifery care: the scope for evaluation. Report of an NHSE funded project 'Evaluation of New Midwifery Practices'. Oxford: National Perinatal Epidemiology Unit, 1997.

27 Mason V. Women's experience of maternity care: a survey manual. Social Survey Division of OPCS, London: HMSO, 1989.

28 Ware JE, Snyder MK, Wright WR. Development and validation of scales to measure patient satisfaction with health care
services. Volume 1. Part A: Review of literature, overview of methods, and results from construction of scales. Springfield, methods, and results from construction of scales. Springt

29 Smith LF. Views of pregnant women on the involvement of GPs in maternity care. Br f Gen Pract 1996;46:101-4. 
30 Smith LFP. Beliefs about the midwife's role in home and hospital deliveries. Br F Midwifery 1996;4:135-40.

31 Bryman A, Cramer D. Quantitative data analysis: a guide for social scientists. London: Routledge, 1994.

32 Baker R. Use of psychometrics to develop a measure of patient satisfaction for general practice. In: Fitzpatrick R, Hopkins A, eds. Measurement of patients' satisfaction with their care. London: Royal College of Physicians, 1993.
33 Gready $M$, Newburn $M$, Dodds R, et al. Birth choices: women's expectations and experiences. London: National women's expectations and

34 Garcia J. Mothers' views and experiences of care. In: Marsh G, Renfrew M, eds. Community-based maternity care. Oxford: Oxford University Press, 1999.

35 McKennell A. Attitude measurement: use of coefficient alpha with factor or cluster analysis. In: Brynner J, Stribley KM, eds. Social research: principles and procedures. London: Longman, 1979 .

\section{Appendix}

Scales derived by principal components analysis (PCA) of WOMBLSQ4. Scales are intuitively named followed by their component questions. Scale means, standard deviations, percentage of variance explained by scale and Cronbach alpha coefficients are given. The final scale about general satisfaction was omitted from PCA with varimax rotation and Kaiser normalisation. Question numbers represent their order on the final questionnaire; negatively worded questions are shown with a minus sign.

\begin{tabular}{|c|c|c|}
\hline Scale & Name (Cronbach's alpha, mean scale score, sd, \% variance explained) & Coefficient \\
\hline 1 & Professional support $($ alpha $=0.91$, mean scale score $=72.3, \mathrm{SD}=20.1, \%$ variance $=27.0)$ & \\
\hline Q7 & All my labour carers were very supportive & 0.830 \\
\hline Q13 & Carers always listened very, very carefully to everything that I had to say & 0.734 \\
\hline Q19 & During labour there was always a carer to explain things so that I could understand & 0.696 \\
\hline Q27 & All my carers treated me in the most friendly and courteous manner possible & 0.838 \\
\hline Q32 & My carers couldn't have been more helpful & 0.797 \\
\hline 2 & Expectations $($ alpha $=0.90$, mean scale score $=59.0, \mathrm{SD}=27.7, \%$ variance $=7.9)$ & \\
\hline Q1 & My labour went totally normally & 0.842 \\
\hline Q11 & The labour went nearly exactly as I had hoped that it would & 0.868 \\
\hline Q17 & The delivery went almost completely as I had hoped that it would & 0.866 \\
\hline Q22 & My labour was just about the right length & 0.749 \\
\hline 3 & Home assessment $($ alpha $=0.90$, mean scale score $=54.3, \mathrm{SD}=23.5, \%$ variance $=7.7)$ & \\
\hline Q8 & I should have had a home assessment in early labour $(-)$ & 0.838 \\
\hline Q15 & $\begin{array}{l}\text { When I thought that my labour had started, I would have liked a carer to come and see me at } \\
\text { home to confirm that I had }(-)\end{array}$ & 0.918 \\
\hline Q28 & Early home assessment of me in labour would have been very helpful (-) & 0.922 \\
\hline 4 & Holding baby $(\mathrm{alpha}=0.87$, mean scale score $=74.2, \mathrm{SD}=20.5, \%$ variance $=7.3)$ & \\
\hline Q3 & I got to see my baby at exactly the right time after she/he was born & 0.811 \\
\hline Q10 & After my baby was born, I was not given him/her quite as soon as I wanted (-) & 0.872 \\
\hline Q18 & I needed to hold my baby a little earlier than I did (-) & 0.864 \\
\hline 5 & Support from husband $($ alpha $=0.83$, mean scale score $=72.7, \mathrm{SD}=21.2, \%$ variance $=5.8$ ) & \\
\hline Q2 & My birth partner/husband helped me to understand what was going on when I was in labour & 0.778 \\
\hline Q23 & My birth partner/husband couldn't have supported me any better & 0.891 \\
\hline Q29 & I could have had a bit more help from my birth partner/husband (-) & 0.889 \\
\hline 6 & Pain in labour $($ alpha $=0.83$, mean scale score $=64.0, \mathrm{SD}=21.8, \%$ variance $=5.5)$ & \\
\hline Q9 & I should have been offered something more to relieve my labour pains $(-)$ & 0.762 \\
\hline Q20 & I got excellent pain relief in labour & 0.753 \\
\hline Q26 & More pain relief would have made my labour easier $(-)$ & 0.826 \\
\hline 7 & Pain after delivery $($ alpha $=0.65$, mean scale score $=57.6, \mathrm{SD}=21.0, \%$ variance $=4.8)$ & \\
\hline Q6 & $\begin{array}{l}\text { I should have been offered something more to relieve the pains I had after my baby was born } \\
(-)\end{array}$ & 0.632 \\
\hline Q16 & I was in a fair bit of pain immediately after the birth $(-)$ & 0.791 \\
\hline Q31 & I didn't need a lot of pain relief after the birth & 0.779 \\
\hline 8 & Continuity (alpha $=0.82$, mean scale score $=38.8, \mathrm{SD}=28.2, \%$ variance $=4.4$ ) & \\
\hline Q5 & At the start of my labour I knew my carers very well & 0.892 \\
\hline Q24 & I knew the carer(s) present at the birth of my baby & 0.885 \\
\hline 9 & Environment $($ alpha $=0.80$, mean scale score $=61.6, \mathrm{SD}=23.7, \%$ variance $=3.7)$ & \\
\hline Q4 & My birth room was a little impersonal and clinical (-) & 0.888 \\
\hline Q14 & The area where I gave birth was very pleasant and relaxing & 0.748 \\
\hline 10 & Control $($ alpha $=0.62$, mean scale score $=53.0, S D=22.2, \%$ variance $=3.3)$ & \\
\hline Q21 & Everyone seemed to tell me what to do in labour (-) & 0.819 \\
\hline \multirow[t]{2}{*}{ Q30 } & Labour was just a matter of doing what I was told by my carers (-) & 0.842 \\
\hline & General satisfaction (alpha $=0.75$, mean scale score $=53.1, \mathrm{SD}=12.5)$ & \\
\hline Q12 & The way my labour care was provided could not have been improved & N/A \\
\hline Q25 & I am satisfied with just one or two things about the labour care that I received (-) & N/A \\
\hline
\end{tabular}

